\title{
Study on Gas Drainage Technology of Opening Closed Roadway
}

\author{
$\mathrm{Xu} \mathrm{Zunyu}{ }^{1,2, *}$ \\ ${ }^{1}$ National Key Laboratory of Gas Disaster Detecting, Preventing and Emergency Controlling, Chongqing 400037, China \\ ${ }^{2}$ Gas Research Institute, Chongqing Research Institute Co., Ltd., China Coal Technology Engineering Group, Chongqing 400037, \\ China
}

\begin{abstract}
In order to ensure the safe and rapid emission of high concentration gas when the mine opens the closed roadway, the gas emission method of the measure hole on the closed wall of the roadway and the extraction hole through the head of the roadway are studied. It solved the problems of difficult control of air volume, long gas emission time, easy overrun of return air flow gas concentration and large influence range in closed roadway gas emission. The practical results show that after the closed wall of $-580 \mathrm{~m}$ track stone gate roadway is opened, the gas concentration in the airflow is $0.18 \%$, and the gas emission time is $2 \mathrm{~min}$, which greatly shortens the gas emission time. There is no abnormal phenomenon in the segmented gas emission, and the safe gas emission is realized.
\end{abstract}

\section{Introduction}

Gas emission is an important work in the process of coal mine production, and it is also a dangerous work. The closed roadway will accumulate a large amount of highconcentration gas after a long period of closure. When the closed wall is opened to restore the ventilation and emission of gas, it is prone to accidents. How to solve the gas problem in the closed roadway safely, efficiently and reliably is the top priority to ensure the recovery of roadway production[1]. It is difficult to ensure that the gas concentration does not exceed the limit after the discharged gas is mixed with the total air pressure and airflow by using the traditional gas drainage methods such as increasing resistance method, barrel three-way method and barrel stagger method[2-5]. In this paper, through the discussion of various methods of gas emission in the closed wall, the "borehole drainage" gas emission technology is proposed, and the safe and efficient gas emission is realized after the closed wall is opened in the underground closed roadway. The gas emission scheme is optimized, and the technical method is improved, which provides a reference for the reasonable gas emission in other mines.

\section{Gas drainage technology in closed wall}

In general, the local ventilators and ducts in closed roadways have been removed, and the local ventilators and ducts need to be re-installed before discharge. Gas discharge is usually carried out by sectional discharge methods, mainly "sectional discharge method for controlling air volume" and "sectional discharge method after pumping". The sectional discharge method of controlled air volume is divided into resistance increasing discharge method, three-way ventilation discharge method and staggered discharge method. The sectional discharge method after pumping is divided into closed pipe drainage and drilling drainage, each method has its own advantages and disadvantages and scope of application.

(1) Sectional emission method

Preparatory work: Install local fans, extend the air duct to the airtight wall, and equip enough air ducts according to the length of gas drainage roadway; Prepare $\mathrm{CH}_{4}, \mathrm{CO}, \mathrm{O}_{2}$ portable instrument, $0-10 \%, 0-100 \%$ optical gas machine, and hang a gas sensor or methane sensor at the junction of the first air flow to monitor the gas concentration of the return air at any time; The compressed air and water supply pipes shall be extended to the front of closing, and the normal air and water supply shall be ensured; Equipped with copper hammer, copper drill and copper crowbar; A telephone is set up at each gas drainage warning place.

Break the airtight: After the power is cut off and the warning is in place, open the newly installed local fan. Before opening and closing, spray water on the whole closed surface to make the whole closed surface wet and ensure the smooth retreat. The rescue team uses copper tools such as copper drill and hammer to dig a hole above the closed wall. At first, the air duct should not face the closed wall, and the wind direction should be controlled according to the concentration of gas blown out from the closed wall. When the concentration of gas discharged is less than $1.5 \%$, the air duct can lean to the closed wall, and gradually move to the hole on the closed wall, and then slowly expand the hole until all the air ducts are inserted into the hole, When the discharged gas is diluted evenly and less than $1.5 \%$, the sealed gas

* Corresponding author: xuzunyu@163.com 
can be removed and the sectional gas discharge can be implemented.

Segmented gas drainage: After closed removal, the rescue team shall check the gas in the roadway $5 \mathrm{~m}$ away from the air duct outlet. When the gas concentration near the air duct outlet in the roadway falls below the limit, the air duct outlet can be reduced, the air flow range can be increased, and the gas in front can be blown out; When the gas concentration drops down, connect a short air duct and increase the air flow range to discharge the gas in front; Take down the short air duct and replace it with the long air duct $(10 \mathrm{~m})$, and continue to discharge the accumulated gas in front of the tunnel until the tunnel head-on. After exhausting the gas in the roadway, the rescue team members should comprehensively check the concentration of gas, oxygen and harmful gas in all parts of the roadway. If there is still gas and harmful gas in some places exceeding the limit or the oxygen concentration is lower than $20 \%$, the method of disconnecting the air duct joint can be used to remove the gas in the section or increase the oxygen concentration in the place.

(2) Resistance-increasing emission method

Strapping air duct method: Before breaking the closed gas discharge, the air duct is strapped with rope to a certain extent to reduce the cross-sectional area of the air duct. By increasing the resistance of the air duct and controlling the air supply at the outlet of the air duct, the gas concentration at the return air roadway is controlled below $1.5 \%$. When the gas concentration discharged from the single end roadway drops, gradually release the rope until it is fully released, and extend the air duct forward, The method of recycling the strapping air duct is used to discharge the gas in the roadway section by section.

Shielding fan method: Cover a part of the air inlet of the local fan with wood or old belt, and control the air flow by increasing the resistance of the local fan and controlling the suction volume of the local fan.

This method is to increase the load of the local fan artificially. If the time is too long, it is easy to cause mechanical and electrical accidents due to the excessive load of the local fan motor. Therefore, it is only suitable for the places where the gas drainage roadway is not long and the gas drainage work can be finished in a short time.

(3) Exhaust method of three-way duct ventilation

When installing the local fan and laying the air duct, a section of three-way air duct shall be laid at the outlet of the local fan air duct switching device. When discharging gas, most of the air supplied by the local fan into the air duct flows into the roadway through the "three-way", and a small part of the air is sent into the single ended roadway through the air duct outlet, so that the gas concentration at the return air lane is controlled below $1.5 \%$, The rope can be used to gradually bind the air duct "three-way" to increase the air flow into the single end roadway until it is completely solid, and the air duct can be extended forward section by section. Similarly, the method of controlling the air supply volume by binding the three-way air duct is used to discharge gas section by section until the gas discharge is completed. When the noise is large and the roadway is long, it is inconvenient for the air volume control personnel to contact with the extension duct personnel, so it is difficult to achieve unified coordination and command, and it is easy to cause gas accidents.

(4) Barrel staggered discharge method

The gas concentration near the exit of the roadway stroke tube is reduced to below the limit, which can reduce the outlet of the wind tube and increase the air flow range, and blow out the gas ahead. When the gas concentration drops, add a short wind tube, using the way of wind tube staggered docking to control the air volume into the single roadway, according to the discharge of gas concentration to control the size of the wind tube docking, until the wind tube fully docking, the same method of increasing the air flow range to discharge the gas ahead, take the short wind tube to replace the long wind tube and continue to use the method of wind tube staggered to discharge the gas ahead until the roadway head.

(5) Drainage method of connecting pipe before opening the closed wall

Before unsealing the closed wall, connect one measure pipe on the closed wall with the gas drainage system, open the other measure pipe, use the negative pressure of the gas drainage system to carry out roadway drainage, and check the gas concentration in the gas drainage pipeline. When the gas concentration drops, open and close the gas drainage according to the sectional drainage method. This method is limited in the range of gas drainage in the roadway, and can only drainage gas near the closed wall, so the drainage range is small.

(6) Drilling drainage method

During the closure of the roadway, the gas accumulates in a static state near the roof of the roadway. When connected with the external environment, the air balance in the roadway is broken, and the gas will flow to the side with low pressure. According to this feature, through the construction of boreholes in the adjacent roadway to the front of the closed roadway, the boreholes are connected to the gas drainage system, and the negative pressure is formed in the closed roadway. The measure holes on the closed wall are opened, so that the gas in the roadway is circulated and flowed, and the ventilation system is formed. The high concentration of gas in the closed roadway is pumped into the gas pipeline through the boreholes, and the gas concentration in the closed roadway is reduced. When the gas concentration decreases, the segmented emission method is used to discharge gas.

\section{Engineering applications}

\subsection{Engineering overview}

Xinji No.1 mine is located in Fengtai County, Huainan City, Anhui Province. The designed annual output is 1.8 $\mathrm{MT} / \mathrm{A}$, the mine field is $6.85 \mathrm{~km}$ long, $3.65 \mathrm{~km}$ wide 
from north to south, and the area is about $25 \mathrm{~km} 2$. There are 5 shafts in the mine, 3 shafts including mixing shaft, auxiliary shaft and central air shaft in the central industrial site, and 2 shafts including West air shaft and west auxiliary shaft in the West Wing of the mine. The mine ventilation system adopts the mixed ventilation mode, the mixed shaft, the auxiliary shaft and the west auxiliary shaft are the air inlet shaft, the central air shaft and the west air shaft are the air return shaft, and the central air shaft and the west air shaft are respectively installed with two main fans, one for use and one for standby. The mine belongs to the coal and gas outburst mine, the absolute gas emission is $21.81 \mathrm{~m}^{3} / \mathrm{min}$, the absolute carbon dioxide emission is $5.7 \mathrm{~m}^{3} / \mathrm{min}$, the permanent gas drainage system is built on the ground, and the pipeline is laid to the underground through drilling. Due to the adjustment of mine production continuity planning, the heading roadways such as the North Central - $580 \mathrm{~m}$ track crosscut are closed. After 2 years of sealing, it is planned to open the sealing wall of the North Central - $580 \mathrm{~m}$ track crosscut to discharge the gas in the roadways.

There are two permanent closed walls at the outer entrance of the $-580 \mathrm{~m}$ track stone gate roadway in the north central of Xinji No.1 Coal Mine. The closed wall is a tile-rock structure, and the spray grouting treatment is carried out. There is one observation hole $(\varphi 20 \mathrm{~mm})$ on the closed wall, two measure pipes ( $\varphi 108 \mathrm{~mm}$ ), and two drainage pipes ( $\varphi 108 \mathrm{~mm})$. The thickness of the closed wall is $900 \mathrm{~mm}$, the total length of the closed area is about $167 \mathrm{~m}$, the average section of the roadway is 16.3 $\mathrm{m}^{2}$, and the gas concentration in the closed wall is $94 \%$. It is expected that the gas accumulation in the roadway is $2558.8 \mathrm{~m}^{3}$. In the early stage of opening the closed wall, the method of connecting pipe drainage is adopted, and the gas drainage system is used to drain the gas in the closed wall, and the gas concentration will not drop after it is reduced to $83 \%$.

\subsection{Gas emission method}

During the closure period of the single ended roadway, the gas accumulates near the roof of the roadway and is in a static state. When it is connected with the external environment, the air balance in the roadway is broken, and the gas will rush to the side with low pressure. According to this characteristic, through the construction of boreholes from the adjacent roadway to the closed roadway head-on, the boreholes are connected with the gas drainage system to artificially form a negative pressure, and at the same time, the measure holes on the closed wall are opened, the gas in the roadway circulates and flows, forming a ventilation system, and the high concentration gas in the closed space is pumped into the gas pipeline through boreholes, so as to reduce the gas concentration in the closed roadway space, To achieve the purpose of intrinsically safe gas drainage. The schematic diagram of gas drainage in the closed wall is shown in Figure 1.

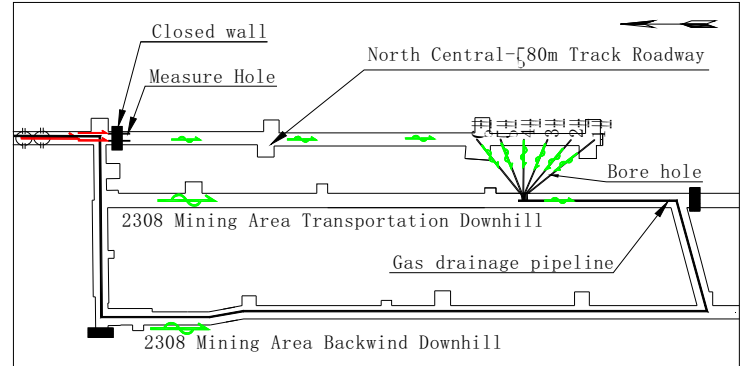

Fig. 1. "Borehole drainage" gas drainage technology schematic diagram

\subsection{Gas drainage scheme and measures}

\subsubsection{Implementation plan}

At the Sancha gate of return air downhill in 2308 mining area and transportation downhill in 2308 mining area, a tee is added to the gas drainage pipeline and extended to the construction borehole of transportation downhill in 2308 mining area. The layout of gas drainage system is as follows:

Ground gas pumping station $\rightarrow$ ground gas drilling $\rightarrow-430$ m return air crosscut $\rightarrow-450$ m central return air crosscut $\rightarrow-450 \mathrm{~m}$ main crosscut north extension $\rightarrow$ North Central 13 coal track downhill $\rightarrow$ North Central $580 \mathrm{~m}$ track crosscut outer section of joint roadway $\rightarrow$ 2309 mining area exploration $\rightarrow 2308$ mining area return air downhill $\rightarrow 2308$ mining area transportation downhill

In 2308 mining area, six gas drainage boreholes are constructed head-on in the northward Central - 580m rail crosscut lane. The design of drilling parameters is shown in Table 1. After the completion of drilling construction, connect the drilling hole with the gas drainage pipeline, open the measure hole on the sealing wall of the North Central $-580 \mathrm{~m}$ rail crosscut lane, and observe the gas concentration in the drainage pipe every day. A set of $30 \mathrm{~kW}$ counter whirlwind machine is installed outside the two air doors of the North Central - 580m track crosscut lane. The air duct is extended to the front of the airtight wall of the North Central - 580m track crosscut lane. When the gas concentration in the extraction pipe drops to $1 \%$, the gas is discharged by sections according to the staggered method of the air duct.

Table 1. Design of extraction boreholes

\begin{tabular}{|c|c|c|}
\hline Namber & $\begin{array}{c}\text { Projection distance } \\
\text { of final hole profile } \\
\text { (m) }\end{array}$ & $\begin{array}{c}\text { Horizontal } \\
\text { projection distance of } \\
\text { final hole (m) }\end{array}$ \\
\hline 1\# & 31 & 30.7 \\
\hline $2 \#$ & 31 & 25.8 \\
\hline $3 \#$ & 31 & 22.2 \\
\hline $4 \#$ & 31 & 20.8 \\
\hline $5 \#$ & 31 & 22 \\
\hline $6 \#$ & 31 & 25.5 \\
\hline
\end{tabular}




\subsubsection{Safeguard measures}

(1) The drilling construction personnel shall pump out the drilling in strict accordance with the design to ensure the connection between the drilling and the closed roadway. After the drilling construction is completed, the screen pipe shall be set down according to the requirements, and the drilling hole shall be sealed tightly to ensure no air leakage.

(2) The gas concentration in the drainage pipe shall be observed every day after the drilling stubble drainage, and the record shall be made to observe the change of gas concentration.

(3) Before gas drainage, special gas drainage measures for opening and closing shall be prepared, and the measures shall be implemented to every person participating in gas drainage, and records shall be made. Before breaking the airtight gas drainage, it is necessary to confirm the influence scope of the gas drainage route. After the power failure, evacuation and warning are carried out in place, the rescue team members use copper tools such as copper hammer and copper drill to break the airtight gas drainage.

(4) When discharging gas, the amount of gas shall be controlled to ensure that the gas at the mixing place of the discharged air flow and full air pressure air flow does not exceed $1.0 \%$ (strengthen management) and the $\mathrm{CO}_{2}$ concentration does not exceed $1.5 \%$. It is strictly forbidden to use "one air blowing". The rescue team is responsible for observing the gas change at the mixing place.

(5) After the gas is discharged to the front, the rescue team must comprehensively check the gas concentration in each part of the roadway. It is confirmed by inspection that the gas concentration in the airflow of the whole roadway is not more than $0.8 \%$, the $\mathrm{O}_{2}$ concentration is not less than $20 \%$, the $\mathrm{CO}_{2}$ concentration is not more than $1.5 \%$, and the concentration of other harmful gases is not more than the provisions of the "coal mine safety regulations". When the gas concentration does not change, the, Only then can we confirm that the gas drainage work in this place is completed.

\subsection{Gas emission effect}

On January 8, 2018, the construction of the drainage boreholes in the North Central - 580m rail crosscut was started in the middle shift. The first boreholes were completed in the night shift on January 9, and the construction was completed on January 12. A total of 6 boreholes were drilled. The boreholes were drained in accordance with the principle of "drilling in one, drainage in one". At the same time, the closed wall measure holes in the North Central - 580m rail crosscut were opened. By January 22 , the gas concentration in the drainage pipe was reduced from $83 \%$ to $0.4 \%$, The effect of gas drainage is obvious. On March 1, 2018, after the sealing wall was unsealed, the gas concentration in the air flow was $0.18 \%$, and the gas was discharged in sections until the head-on gas was normal, and the gas discharge work was safely completed.
After the closed tunnel of Shimen lane of North central-580m track is drained by connecting pipes before the early closing, it is estimated that the gas accumulation in this roadway is $2259.3 \mathrm{~m}^{3}$, and the air supply capacity of $30 \mathrm{~kW}$ contrarotating local fan is about $550 \mathrm{~m}^{3} / \mathrm{min}$. in order to ensure that the gas concentration discharged is not more than $1.0 \%$, the maximum gas discharge volume shall not exceed $5.5 \mathrm{~m}^{3} / \mathrm{min}$, and the estimated gas discharge time is about $411 \mathrm{~min}$, After drilling and drainage, it is estimated that the gas accumulation in this roadway is $10.89 \mathrm{~m}^{3}$, and the gas emission time is about $2 \mathrm{~min}$ (excluding the time of breaking the airtight and extending the air duct), which greatly shortens the gas discharge time.

\section{Conclusion}

(1) The method of drilling to drain the gas in the closed roadway is adopted to drain the high-concentration gas in the closed space into the gas drainage pipeline, which has strong operability, high reliability and small influence range.

( 2 ) Reducing the gas concentration in the closed roadway to less than $1 \%$ not only greatly shortens the gas emission time, but also eliminates the risks of gas overrun, suffocation or explosion in the process of gas emission, so as to achieve safe gas emission. The effect is significant in practice, and it has great safety benefits and social stability benefits.

( 3 ) There are some limitations in the practical application of borehole gas drainage technology, and there is a situation that borehole construction cannot be carried out to the front, which needs further research, but still has certain reference significance.

\section{Acknowledgments}

General project of Chongqing Research Institute Co., Ltd (2020YBXM23).

\section{References}

1. Li Sihao, Zhang Chao, Lu Lisong, Wang Jijun. Research and practice of combined gas drainage technology in closed roadway of high gas mine [J]. Coal technology, 39 (01): 145-148 (2000)

2. Zhao Lu Hua, Jin Ze Ping, Bao Ji Ming, et al. Application of gas drainage method in Tucheng Mine [J]. Mining safety and environmental protection S1: $53-54$

3. Yue Zhen, several common methods of gas drainage in single end roadway $[\mathrm{J}]$, science and technology horizon, 028: 404-404 (2012)

4. Jiang Guoqiang. Discussion on several common methods of gas drainage in single end roadway [J]. Science and technology innovation guide, 33: 207$208+210(2008)$

5. Zhang Guoshu, ventilation safety, (China University of mining and Technology Press, 2000) 